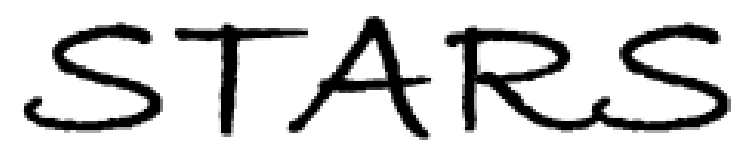

University of Central Florida

STARS

$1-1-2015$

\title{
Paleoprecipitation Reconstruction in the Indus and Ganges Basins by Inverse Modeling of Tree-Ring-Based PDSI
}

\author{
Rahman Davtalab \\ University of Central Florida \\ Dingbao Wang \\ University of Central Florida \\ Tingju Zhu \\ Claudia Ringler
}

Find similar works at: https://stars.library.ucf.edu/facultybib2010

University of Central Florida Libraries http://library.ucf.edu

This Article is brought to you for free and open access by the Faculty Bibliography at STARS. It has been accepted for inclusion in Faculty Bibliography 2010 s by an authorized administrator of STARS. For more information, please contactSTARS@ucf.edu.

\section{Recommended Citation}

Davtalab, Rahman; Wang, Dingbao; Zhu, Tingju; and Ringler, Claudia, "Paleoprecipitation Reconstruction in the Indus and Ganges Basins by Inverse Modeling of Tree-Ring-Based PDSI" (2015). Faculty Bibliography 2010s. 6491.

https://stars.library.ucf.edu/facultybib2010/6491

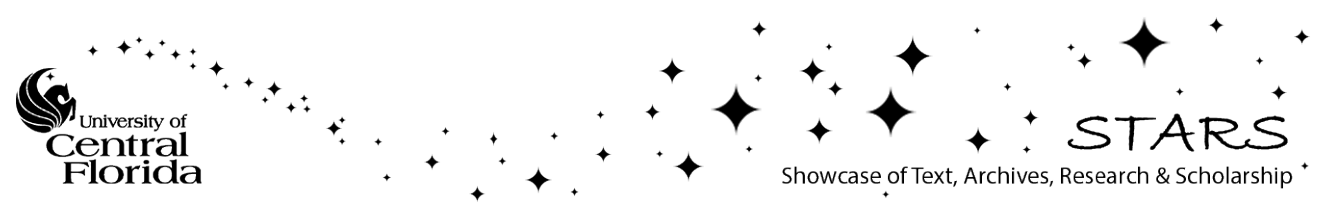




\title{
${ }_{\text {Paleoprecipitation Reconstruction in the Indus and Ganges Basins }}$ by Inverse Modeling of Tree-Ring-Based PDSI
}

\author{
RAHMAN DAVTALAB AND Dingbao WANG \\ Department of Civil, Environmental, and Construction Engineering, University of Central Florida, \\ Orlando, Florida \\ TingJu ZHU AND Claudia RingleR \\ International Food Policy Research Institute, Washington, D.C.
}

(Manuscript received 8 September 2014, in final form 14 January 2015)

\begin{abstract}
The South Asian monsoon is critically important for agricultural production in the region that includes the vast, fertile Indus and Ganges basins. However, the behavior of the South Asian monsoon is not well understood because of its complex nature, and existing instrumental climate records are insufficient for investigating the risks of the low-frequency but high-impact megadroughts that have historically occurred. This paper develops an inverse Palmer drought severity index (PDSI) model to retrieve paleoprecipitation for the region during the time period of 1300-1899, using available data of the water-holding capacity of soil, temperature, and reconstructed PDSI based on the tree-ring analysis of Cook et al.. Temperature data are reconstructed by a regression analysis utilizing an existing temperature reconstruction in an adjacent region and the Pacific decadal oscillation. Based on the retrieved paleoprecipitation, several megadroughts are identified during the reconstruction period. The drought frequency in the Indus basin is higher than that in the Ganges basin. The intensity, frequency, and spatial extent of severe droughts increased from 1300-1899 to 1900-2010. As a signal of climate change, increasing intensity and frequency of severe drought in the Indus and Ganges River basins needs adaptation strategies and drought preparedness measures to secure the food production in this area.
\end{abstract}

\section{Introduction}

Home to close to a billion people, the Indus and Ganges basins (IGB) are the most important socioeconomic regions in South Asia and are among the world's most productive ecosystems (Gupta et al. 2001; Sikka and Ringler 2009). Total cultivation area in this region covers more than 39 million ha, supporting the food security of hundreds of millions of largely poor and barely food-secure people (Aggarwal et al. 2004). Food production in the IGB is closely linked with the magnitude and spatiotemporal pattern of the South Asian

๖ Denotes Open Access content.

Corresponding author address: Dingbao Wang, Department of Civil, Environmental, and Construction Engineering, University of Central Florida, 12800 Pegasus Dr., Suite 211, Orlando, FL 32816. E-mail: dingbao.wang@ucf.edu monsoon (SAM). A precipitation deficit of $10 \%$ from the long-term average can lead to agricultural drought conditions in the IGB area (Sinha et al. 2011; Prasad et al. 2014).

The more-frequent SAM failures over the past 30 years have contributed to the rapid increase in the number of tube wells with cheaper pumps and free electricity in the region (Sinha et al. 2011), which, in turn, led to declining water tables in the northwestern IGB (Aggarwal et al. 2004). The sensitivity of the IGB area to SAM failure was highlighted in 2002, when a severe drought hit major parts of the Indian peninsula and caused a drop in food production (Gadgil et al. 2004). Several studies have focused on understanding the main drivers for SAM failures based on historical data for the purpose of predicting its future behavior (Kumar et al. 2006; Cook et al. 2010; Yi et al. 2011; Yadav et al. 2014; Prasad et al. 2014).

The challenge is that climate observation data are limited in the IGB area. The limited spatial coverage of weather stations and the limited length of data records 

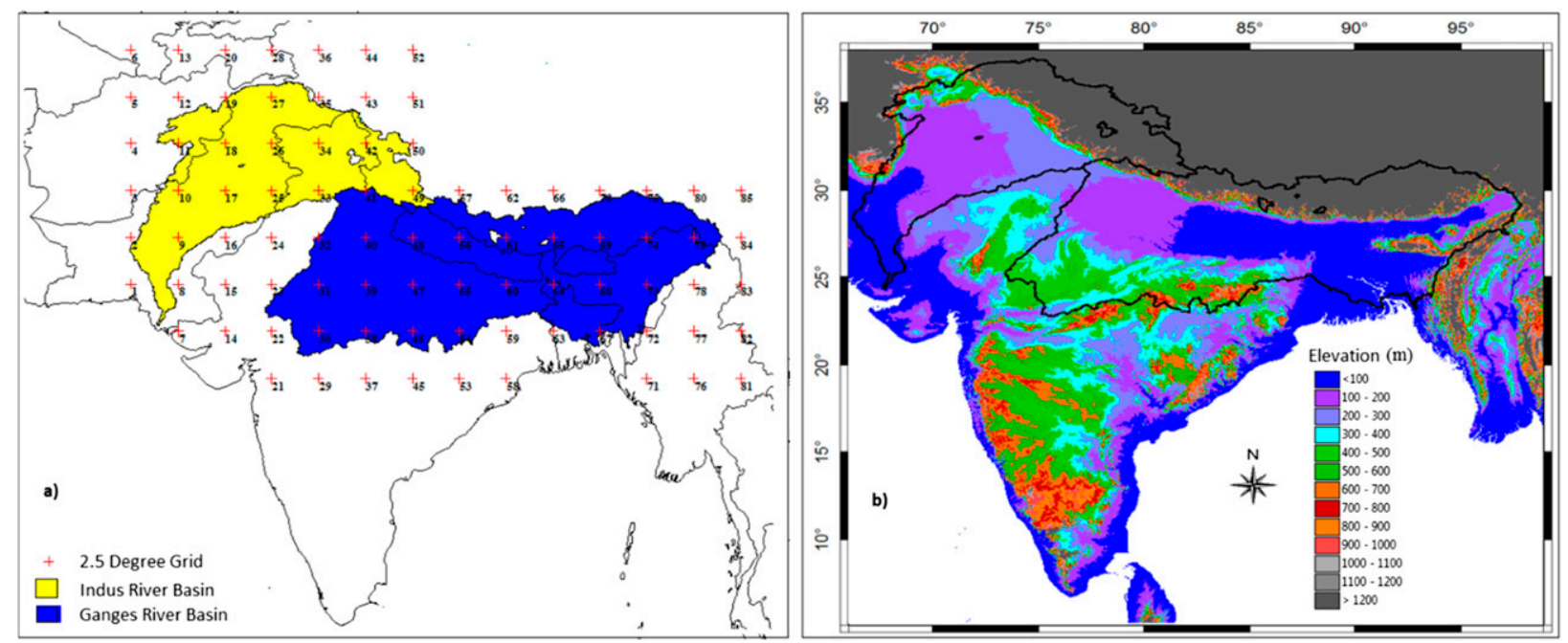

FIG. 1. The study region: (a) the IGB and the grid points of the MADA-PDSI dataset and (b) ground elevation.

are insufficient to address the full variability of SAM and to detect the natural variability of the climate system from anthropogenic signals (McGregor et al. 2010; Cook et al. 2010; Sinha et al. 2011; Li et al. 2011). To address this limitation, climate proxy data are usually used to reconstruct paleoclimatic data (Hughes et al. 1994; Briffa et al. 2001; Tan et al. 2003; McGregor et al. 2010; Golovanova et al. 2012; Elbert et al. 2013; Prasad et al. 2014). These climate proxies are archived in tree rings, ice cores, boreholes, corals, and lake and ocean sediments, and are physical or chemical characteristics preserved in nature that reflect the state of climate in the past (Macias-Fauria et al. 2012). Instrumental records capture droughts that occurred in the past approximately 100 years, but they are too short to assess the reoccurrence of those low-frequency but high-impact droughts. As droughts continue to have devastating impacts on food production and society, it is important to study severe droughts during the past century in a longterm perspective. Paleoclimatic data provide an opportunity for studying drought from the past hundreds to tens of thousands of years (Mishra and Singh 2010).

Despite numerous studies of paleoclimatology around the world, IGB is one of the areas with large gaps in reconstruction data. Shortage of instrumental data and lack of appropriate sources for proxies are the predominant barriers of paleoclimatic studies in this region (Cook et al. 2010). The NOAA National Climatic Data Center (NCDC) provides a major reconstruction data bank for the world, which includes two paleoclimatic

TABLE 1. List of instrumental and reconstruction data used in this study.

\begin{tabular}{llll}
\hline \hline \multicolumn{1}{c}{ Data } & Temporal resolution & Period & Reference \\
\hline 3-month PDSI $\left(2.5^{\circ}\right)$ & Avg over June-August & $1300-2005$ & Cook et al. (2010) \\
Precipitation $\left(0.5^{\circ}\right)$ & Monthly & $1900-2010$ & Willmott and Matsuura (2012) \\
Kathmandu temp & Annual & $1564-1991$ & Cook et al. (2003) \\
Tibetan Plateau temp & Annual & $1400-1995$ & Briffa et al. (2001) \\
Eastern China temp & Annual & $1000-1996$ & Shi et al. (2012) \\
Western China temp & Annual & $1000-1996$ & Shi et al. (2012) \\
China temp & Annual & $1000-1996$ & Shi et al. (2012) \\
ENSO & Annual & $900-2002$ & Li et al. (2011) \\
Niño-1 + 2-Southern Oscillation & Annual & $1300-2006$ & E. R. Cook et al. (2008, meeting presentation) \\
Niño-3-Southern Oscillation & Annual & $1300-2006$ & E. R. Cook et al. (2008, meeting presentation) \\
Niño-3.4-Southern Oscillation & Annual & $1300-2006$ & E. R. Cook et al. (2008, meeting presentation) \\
Niño-4-Southern Oscillation & Annual & $1300-2006$ & E. R. Cook et al. (2008, meeting presentation) \\
PDO & Annual & $993-1996$ & MacDonald and Case (2005) \\
Southern annular mode-Marshall & Annual & $1409-2006$ & Villalba et al. (2012) \\
Southern annular mode-Marshall 30-yr spline & Annual & $1409-2006$ & Villalba et al. (2012) \\
\hline
\end{tabular}


datasets for the IGB (www.ncdc.noaa.gov/data-access/ paleoclimatology-data). The data include 400 years of reconstructed temperature for Nepal (Cook et al. 2003) and data from the Monsoon Asia Drought Atlas (MADA) in the form of the Palmer drought severity index (PDSI) at $2.5^{\circ}$ resolution (Cook et al. 2010).

MADA-PDSI is a paleoclimatic dataset consisting of annual time series of average PDSI for the three summer monsoon months (June-August) during the period of 1300-2005. The MADA-PDSI data are reconstructed from 327 series of tree-ring chronology data and calibrated using the instrumental PDSI by Dai et al. (2004). Therefore, the MADA-PDSI provides valuable information about monsoon variability and failures as well as historical drought characteristics in the IGB region. The MADAPDSI dataset provides a unique opportunity to reconstruct precipitation data, which are valuable for understanding the paleohydrology in IGB because the dataset includes continuous PDSI data back to the year 1300.

The objective of this study is to develop an inverse algorithm to retrieve precipitation data from the reconstructed MADA-PDSI dataset. The inverse algorithm is developed based on the PDSI code of Jacobi et al. (2013). Precipitation is generated by the inverse algorithm by taking PDSI and temperature as the main inputs. This is the first time, based on our knowledge, that an inverse code is developed from PDSI to generate estimations of precipitation.

\section{Study area and data sources}

\section{a. Study sites}

The Indus-Ganges plains in the IGB form the largest consolidated area of irrigated food production with net area of 114 million ha (Sikka and Ringler 2009). Most of
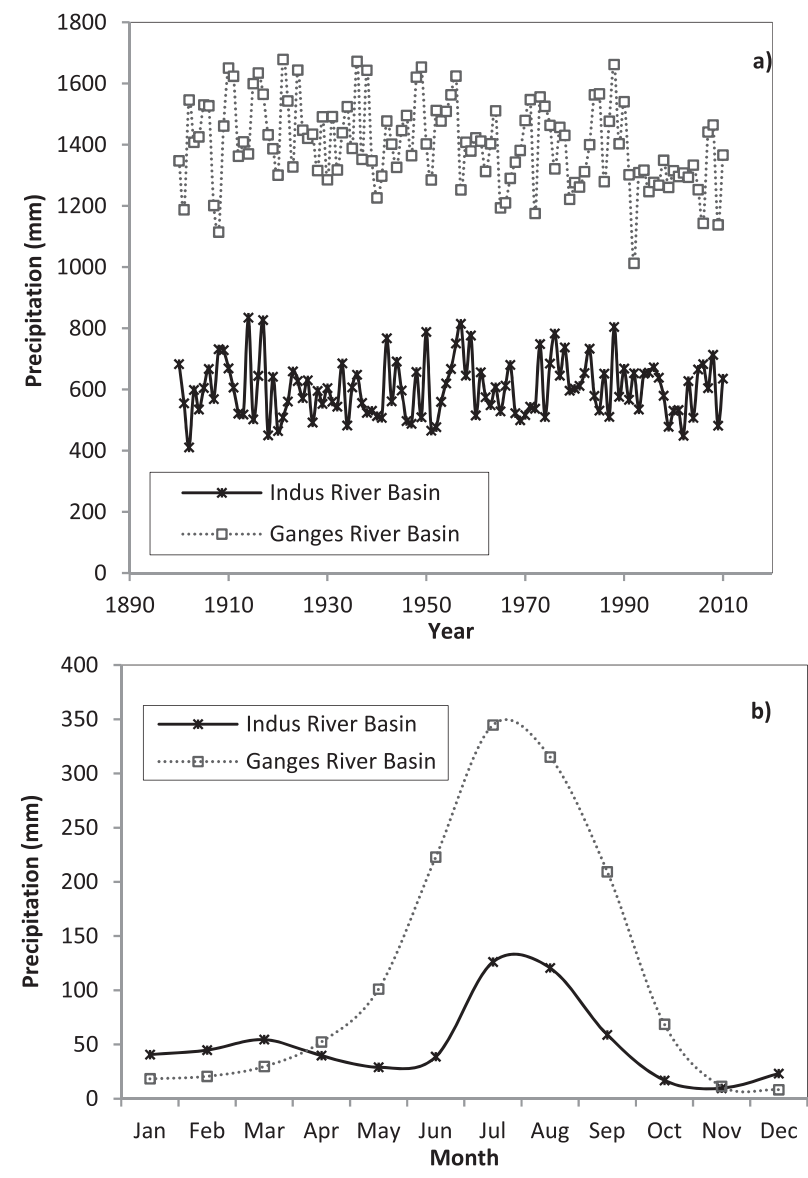

FIG. 2. Precipitation in the IGB during the period of 1900-2010: (a) annual precipitation and (b) mean monthly precipitation.

the close to one billion people continue to rely on agriculture for their livelihoods, and high population growth is a cause for concern in terms of water and food security and resource conservation (Sikka and Ringler 2009).

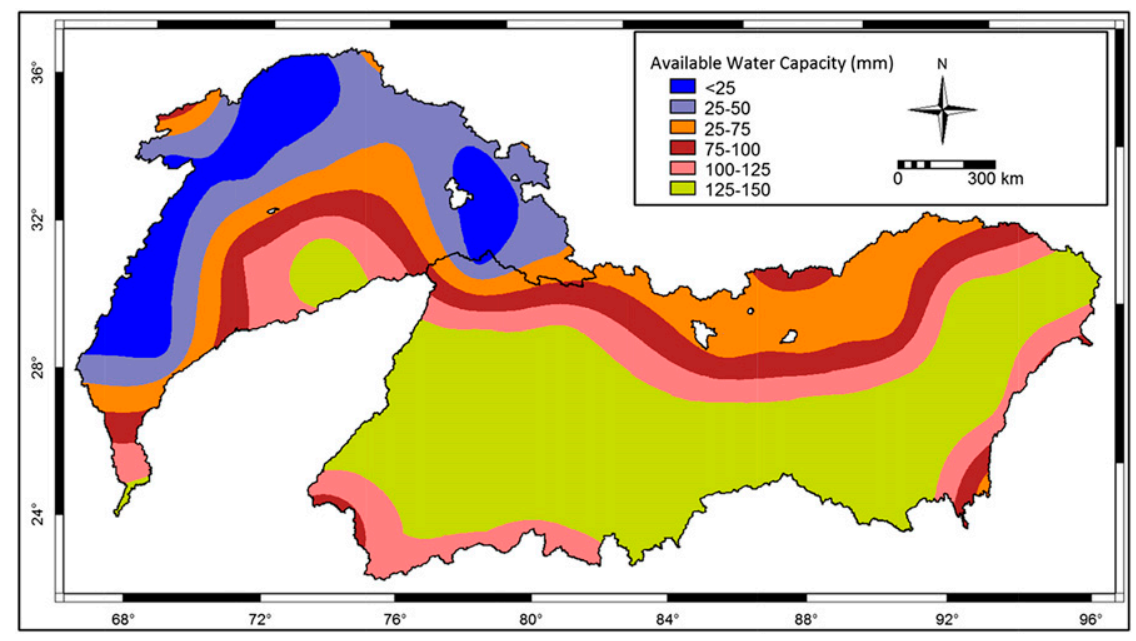

FIG. 3. The distribution of AWC in the IGB area obtained from the HWSD. 


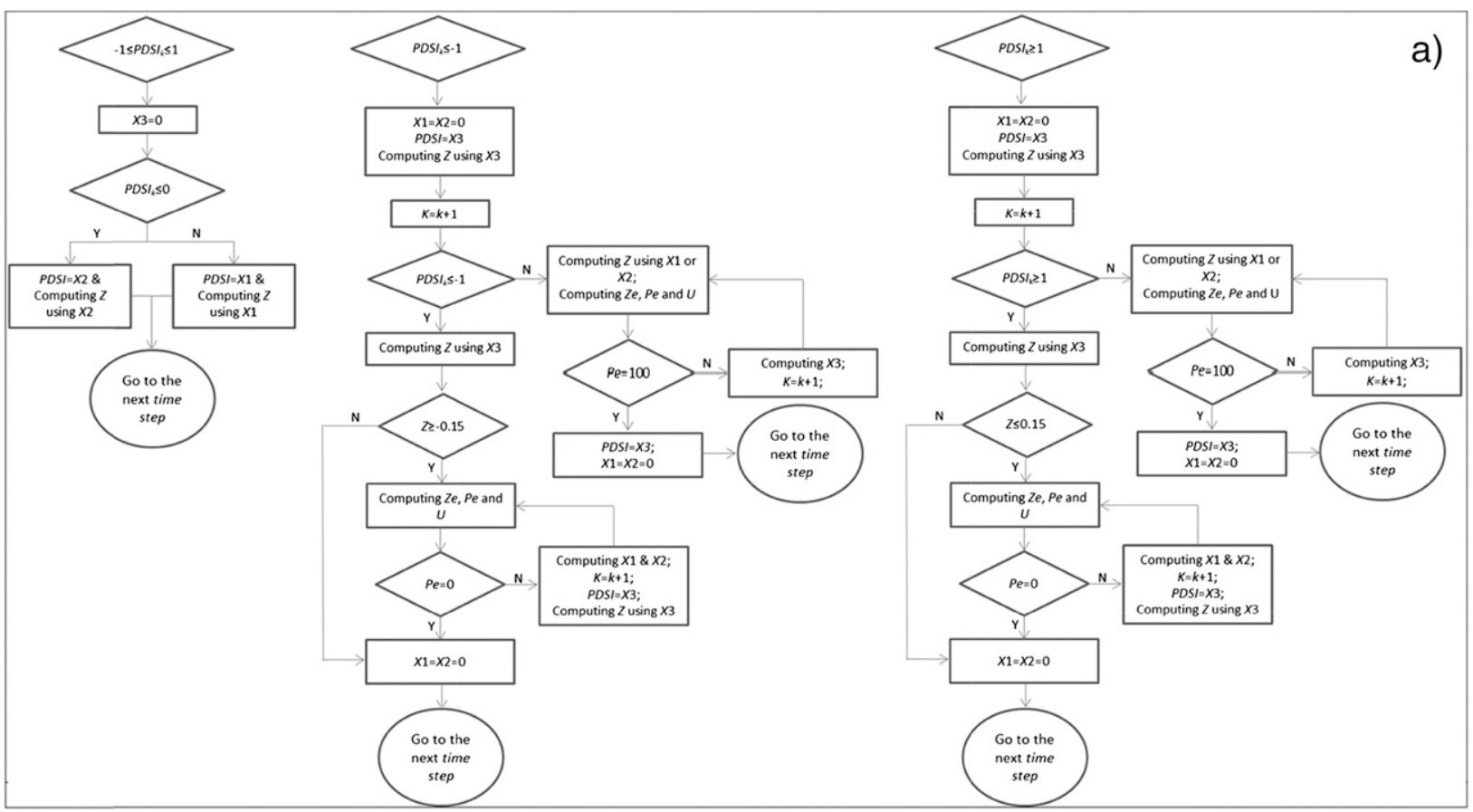

FIG. 4. (a) Flowchart for computing $Z$ values from a PDSI time series. (b) Procedures for retrieving precipitation from $Z$ values.

The economy, environment, and food security in the IGB region have been studied by national and international research communities (Gupta et al. 2001; Nandakumar et al. 2010). The hydroclimatic characteristics in the IGB region are unique because it is bounded by the Himalaya Mountains from the north and by the Indian Ocean tropical belt from the south. As shown in Fig. 1a, the region is divided into two subregions by the Delhi Ridge. The western part consists of the Punjab Plain and the Haryana Plain (Indus), and the eastern part consists of the Ganga-Brahmaputra River basin (Ganges). Figure 1b shows the land surface topography, which varies from sea surface level in the south to more than $8000 \mathrm{~m}$ above mean sea level in the north.

\section{b. Datasets for the instrumental and reconstruction periods}

Table 1 shows the list of data used in this study. The average 3-month PDSI (MADA-PDSI) is the primary dataset for reconstructing precipitation. MADA-PDSI is a gridded dataset for average summer PDSI series, extracted from tree-ring chronologies data back to 1300 . Cook et al. (2010) reconstructed this dataset using the global dataset (GD) of the PDSI for the period of 1870 2002 by Dai et al. (2004). The "Terrestrial air temperature and precipitation: 1900-2010 gridded monthly time series" data with a $0.5^{\circ}$ resolution are used as observations for the instrumental period (Willmott and Matsuura 2012) and are regridded to $2.5^{\circ}$ resolution for matching with the resolution of the MADA-PDSI dataset. The annual precipitation based on this dataset increases from the Indus basin $(600 \mathrm{~mm})$ to the Ganges basin (more than $1500 \mathrm{~mm}$ ), as shown in Fig. 2a. Figure $2 \mathrm{~b}$ shows the mean monthly precipitation during the instrumental period. Precipitation in the Indus basin has two peaks (March and July) because it is located at a transition between the monsoon in the east and the Mediterranean weather system in the west (Karim and Veizer 2002). To estimate precipitation by inverse PDSI modeling, temperature is needed during the reconstruction period. Therefore, in this study, different sources of temperature data from the study region and adjacent regions, as well as a wide range of reconstructed atmospheric indices, are applied for reconstructing temperature data (Table 1 ).

\section{c. Available water capacity}

Available water capacity (AWC) is an input for calculating the PDSI. The AWC values for each grid point are extracted from the Harmonized World Soil Database (HWSD), which is provided by the Food and Agriculture Organization of the United Nations (FAO) and the International Institute for Applied Systems Analysis (Nachtergaele et al. 2012). The spatial resolution of the 


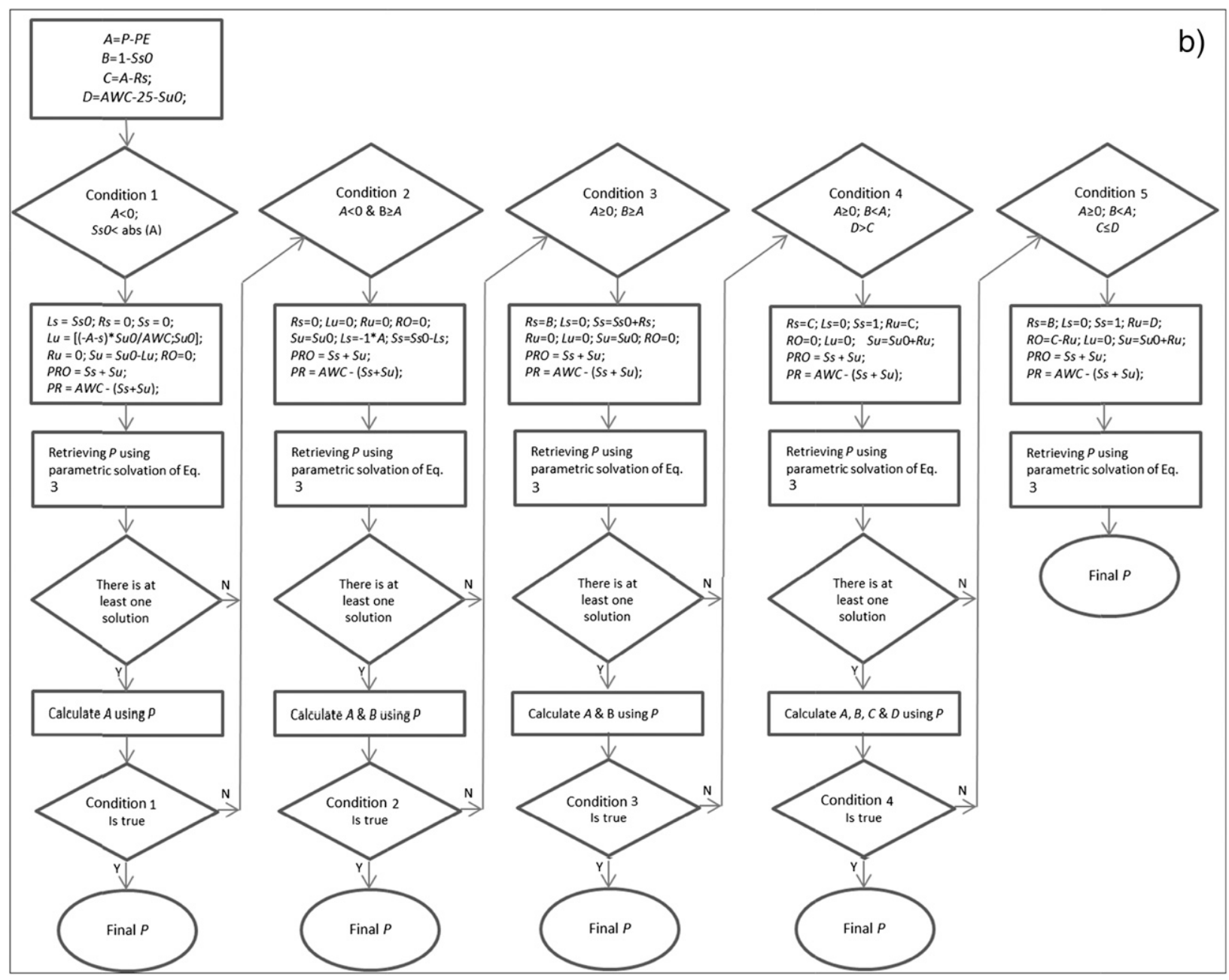

FIG. 4. (Continued)

HWSD is 30 arc s (or $\sim 1 \mathrm{~km}$ ) and there are 53 soil parameters for each grid point, which are saved in a Microsoft Access database. The AWC values are averaged to the grid of MADA-PDSI with a spatial resolution of $2.5^{\circ} \times 2.5^{\circ}$. Figure 3 shows the spatial distribution of AWC values by six categories with intervals of $25 \mathrm{~mm}$. As shown in Fig. 3, AWC varies from less than $25 \mathrm{~mm}$ in the northwestern IGB to $150 \mathrm{~mm}$ in the southern and central IGB, representing higher soil water storage capacities in the central plains.

\section{Methodology}

\section{a. Temperature during the reconstruction period}

Since there is no reconstructed temperature record within the IGB region, reconstructed temperature or climatic indices in nearby regions are utilized through correlation analysis. Areal average temperature (AAT) in the two basins, that is, two lumped annual time series, are reconstructed using linear regression analysis. These two time series are used for reconstructing grid-based temperature using point-by-point regression analysis (Cook et al. 2010). To evaluate the performance of the regression-based temperature reconstruction, the instrumental period (1900-2010) is divided into a calibration period (1941-2010) and a verification period (1900-40).

\section{b. Procedures for computing PDSI}

The PDSI, developed by Palmer (1965), has been widely used for quantifying and monitoring droughts (Dai et al. 2004; Ryu et al. 2010; Mishra and Singh 2010; Wang et al. 2011). The calculation of PDSI relies on a water balance model in which the soil moisture is simulated by two conceptualized soil layers. AWC is a parameter representing the total water capacity in the 
surface and underlying soil layers. The storage capacity for the surface layer is set to $25 \mathrm{~mm}$. Soil water storage cannot be removed from (recharged to) the underlying layer until the surface layer is fully depleted from (replenished in) the surface layer (Alley 1984). When potential evapotranspiration $E_{p}$, which is computed by the method of Thornthwaite (1948), is higher than precipitation $P$, evapotranspiration losses from the surface and underlying layers occur and are computed by

$$
L_{S}=\min \left[S_{S},\left(E_{p}-P\right)\right]
$$

and

$$
L_{U}=\frac{\left[\left(E_{p}-P\right)-L_{S}\right] S_{U}}{\mathrm{AWC}},
$$

where $L_{S}$ and $L_{U}$ are the evapotranspiration losses from the surface and underlying layers, respectively, $S_{S}$ and $S_{U}$ are the amount of water stored in the corresponding soil layer at the beginning of the month (Alley 1984).

Water balance computation results in four coefficients for each month: $\alpha$, the ratio of average actual evapotranspiration to average $E_{p} ; \beta$, the ratio of average actual recharge to potential recharge; $\gamma$, the ratio of average actual runoff to potential runoff; and $\delta$, the ratio of average actual loss to potential loss. The values of $\alpha, \beta, \gamma$, and $\delta$ are computed during the calibration period, which should be a normal climatic period of more than 30 years (Houghton et al. 2001). The moisture anomaly index, denoted as $Z$, is computed as follows:

$$
Z=k_{j}\left[P-\left(\alpha_{j} E_{p}+\beta_{j} \mathrm{PR}+\gamma_{j} \mathrm{PRO}+\delta_{j} \mathrm{PL}\right)\right],
$$

where $j=1,2, \ldots, 12$ is the index for time step (month); $\mathrm{PR}$ is the potential recharge; PRO is the potential runoff; PL is the potential loss; and $k_{j}$ is a spatiotemporal adjustment factor. This factor allows $Z$ values to be compared for different locations and months. Finally, the PDSI value is computed by the following equation, considering the start and end of a dry or wet spell:

$$
X_{i}=0.897 X_{i-1}+Z_{i} / 3,
$$

where $X_{i}$ is the PDSI value for month $i$.

Equation (4) shows that severity of a drought in each month is affected by the drought condition in the previous month. A normal or wet spell, that is, when the value of $X_{i-1}$ is zero, terminates an existing drought. It is essential to find the start and end months of a dry or wet spell for computing the PDSI. To address this, the

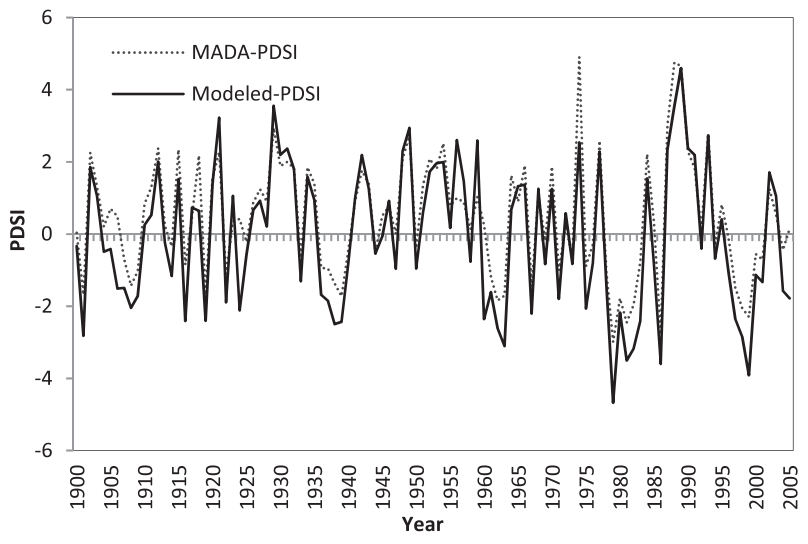

FIG. 5. Comparison of MADA-PDSI and modeled PDSI during the instrumental period at gridpoint 18 .

severity index for an established wet spell (denoted as $X 1$ ), the severity index for an established dry spell (denoted as $X 2$ ), and the severity index for both established dry and wet spells (denoted as $X 3$ ) are computed. The values of $X 1, X 2$, and $X 3$ are calculated by replacing $X$ with these indices in Eq. (4). The value of $X 1$ is nonnegative, while $X 2$ is nonpositive, $X 1$ and $X 2$ are set to zero when the computed values of Eq. (4) violate these restrictions. Based on these three indices, wet or dry spells are identified. The value of one index from $X 1$, $X 2$, or $X 3$ is set to $X$ (i.e., the PDSI value). A dry spell starts when $X 2 \leq-1$ for the first time and a wet spell starts when $X 1 \geq+1$ for the first time. At the start of a drought or wet spell, $X 3$ is set to $X 2 / X 1$. When $X$ approaches normal $( \pm 0.5)$, an established drought or wet spell ends and $X 3$ is set to zero.

The required moisture for reaching an $X$ value of \pm 0.5 in a month, denoted as $Z_{e}$, is used to determine the end of a drought or wet spell. During an established dry spell, $Z_{e}$ is calculated as follows:

$$
Z_{e}=-2.691[X 3(i-1)]-1.5
$$

The dry spell is terminated when $Z(i) \geq Z_{e}$. In an established wet spell, $Z_{e}$ is calculated by

$$
Z_{e}=-2.691[X 3(i-1)]+1.5
$$

The wet spell is terminated when $Z(i) \leq Z_{e}$. Palmer (1965) also defined a percentage probability $P_{e}$ to determine the end of a dry or wet spell. More explanation of the computation of Eq. (4) is provided by Palmer (1965) and Alley (1984). Jacobi et al. (2013) developed a MATLAB code for computing PDSI, and the accuracy of the algorithm has been verified by the drought index data 


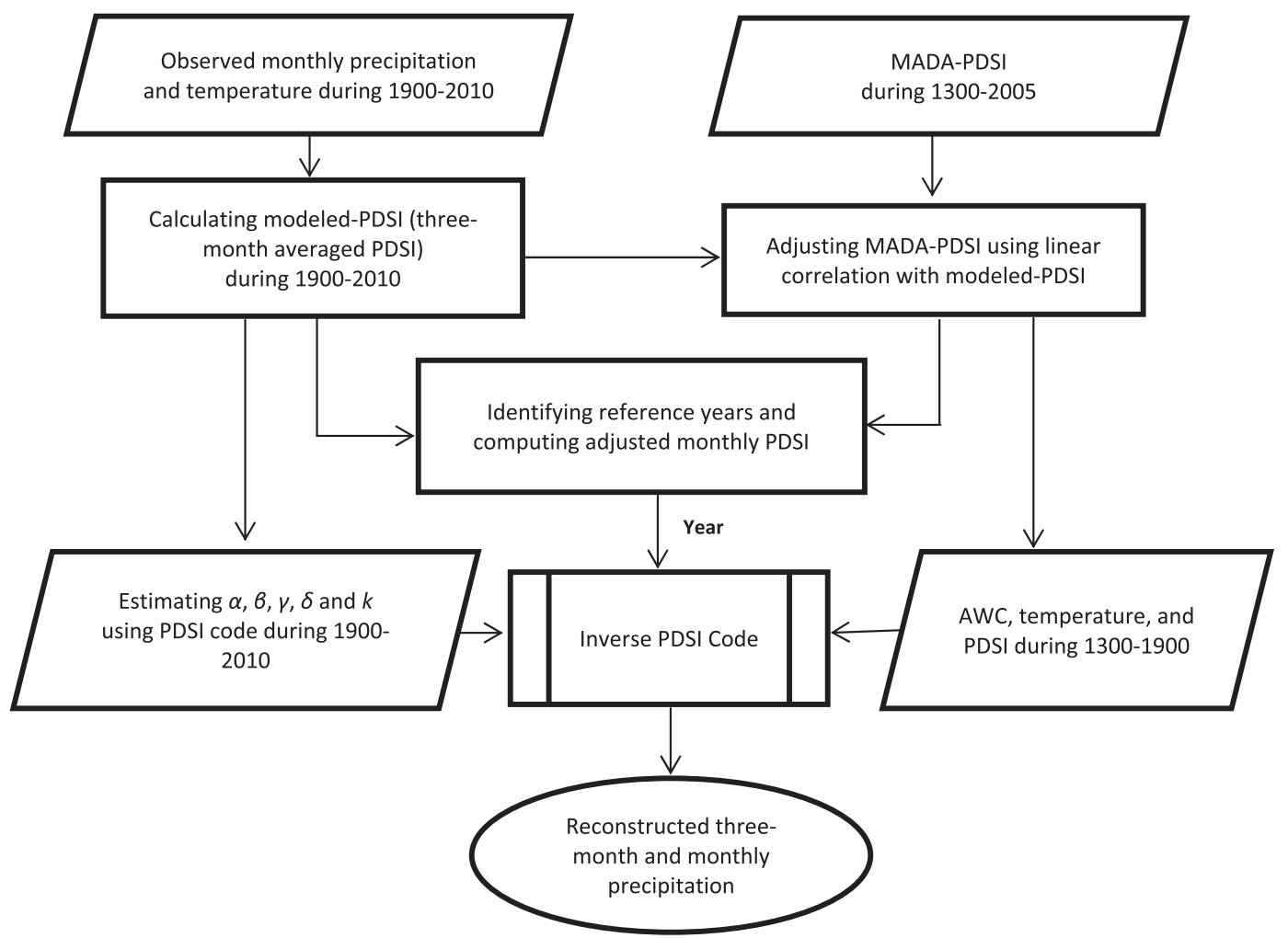

FIG. 6. Flowchart for reconstructing precipitation from the MADA-PDSI dataset.

from the NCDC (http://www1.ncdc.noaa.gov/pub/data/ cirs/). The developed inverse PDSI code in this paper is based on the forward PDSI code developed by Jacobi et al. (2013).

\section{c. Retrieving rainfall by inverse PDSI}

In this study, precipitation during the reconstruction period is unknown, but the PDSI and other parameters and variables are available. We therefore develop an inverse PDSI code in MATLAB for estimating precipitation using AWC, temperature, and PDSI. The values of $k, \alpha, \beta, \gamma$, and $\delta$ are computed by running the forward PDSI code during the calibration period of 1900-2010 when observed precipitation and temperature are available. The values of $k, \alpha, \beta, \gamma$, and $\delta$ are assumed to be the same between the reconstruction and instrumental periods.

There are two major steps in the inverse PDSI algorithm (IP algorithm) shown in Figs. 4a and 4b. The first step is to estimate $Z$ values based on PDSI using Eq. (4). Meanwhile, the values of $X 1, X 2, X 3, Z_{e}$, and $P_{e}$ are computed. The second step in the IP algorithm retrieves precipitation using the $Z$ value (Fig. 4b). In the forward PDSI computation, the procedure for water balance calculations changes based on the difference of precipitation and potential evapotranspiration $\left(P-E_{p}\right)$, the value of AWC, and the amount of available moisture at the beginning of the month in the surface and underlying surface (i.e., $S_{S 0}$ and $S_{U 0}$ ), as shown in Fig. 4b. These situations create five mutually exclusive conditions for computing water balance components. However, precipitation data do not exist for identifying the proper condition that is unknown. Therefore, five mutually exclusive conditions are tested sequentially until a correct one is identified as illustrated in Fig. 4b. For example, the first condition is that the precipitation is less than potential evapotranspiration $(A<0)$ and the available moisture at the beginning of the month in the surface layer is less than the absolute value of $A\left[S_{S 0}<\operatorname{abs}(A)\right]$. Under this condition, $L_{S}, R_{S}, S_{S}, L_{U}, R_{U}$, PRO, and PR can be computed. These computed values are used to retrieve precipitation by solving Eq. (3). If a positive value is obtained for precipitation from Eq. (3), the retrieved value is used to compute $A$ and the original condition [i.e., $A<0$ and $S_{S 0}<\operatorname{abs}(A)$ ] is checked. If the retrieved precipitation meets the condition, the precipitation estimation is obtained and moves to the next time step. Otherwise, the procedure moves to the next condition (i.e., $A<0$ and $B>A$, where $B=1-S_{S 0}$ ) 
until a precipitation estimation is obtained. As discussed in the results section, the developed IP algorithm is validated by comparing the retrieved precipitation during the instrumental period with the observed precipitation.

\section{d. Three-month PDSI during the monsoon season and monthly PDSI}

The MADA-PDSI (3-month PDSI) is the average PDSI value in the monsoon season (June-August). The observed monthly precipitation and temperature data (Willmott and Matsuura 2012) are used for calculating the PDSI during the instrumental period. The average PDSI during the monsoon season is computed and is hereafter called modeled PDSI. As shown in Fig. 5, the discrepancy between the modeled PDSI and MADA-PDSI is due to the differences in the methods and climatic datasets for deriving these two PDSI time series. The MADA-PDSI during the calibration period was based on the computed PDSI by Dai et al. (2004). Since precipitation during the reconstruction period was estimated based on the IP algorithm, the MADA-PDSI during the reconstruction period is adjusted based on the linear regression relationship between MADA-PDSI and modeled PDSI during the period of 1900-2005.

In addition to the 3-month PDSI, monthly PDSI are also reconstructed in this study. The adjusted PDSI for a given year in the reconstruction period is compared with the modeled PDSI in each year from the instrumental period (1900-2010). The absolute values of the difference between adjusted PDSI and modeled PDSI are computed and the year with the minimum absolute value is selected as the reference year. The monthly PDSI distribution in the reference year is selected for the given year in the reconstruction period. Based on this procedure, as shown in Fig. 6, the monthly PDSI for each year in the reconstruction period is computed.

\section{Results and discussion}

\section{a. Reconstructed temperature and potential evapotranspiration}

\section{1) Temperature During $1600-1900$}

Several sources of temperature data are examined for the temperature reconstruction in IGB. The temperature data in Kathmandu have a stronger correlation with the IGB region than other tested datasets (Cook et al. 2003). Therefore, the Kathmandu data during 1600 1900 are chosen for the temperature reconstruction in the IGB region. Based on the observed annual
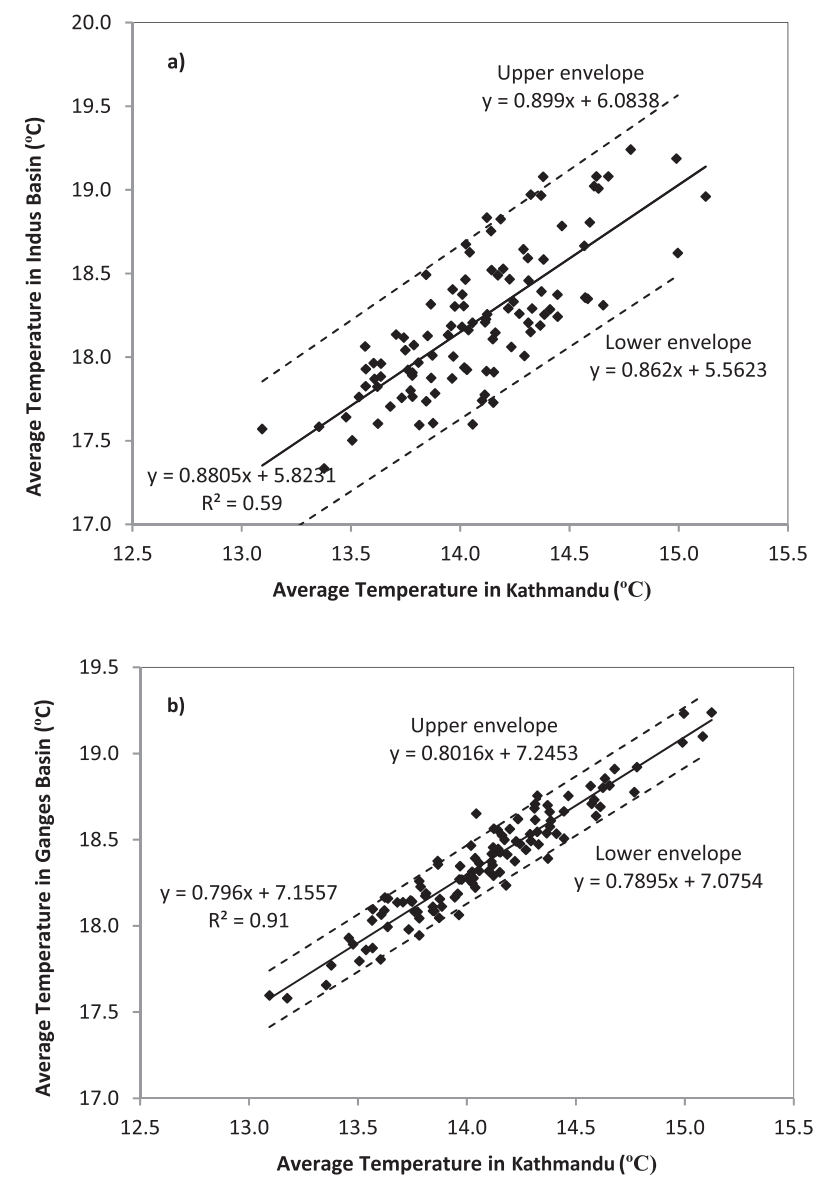

FIG. 7. Temperature correlation between (a) the Indus River basin and Kathmandu and (b) the Ganges River basin and Kathmandu during 1900-91.

temperature data during 1900-91, the correlation of average temperature between the Indus basin (Ganges basin) and Kathmandu is shown in Fig. 7a (Fig. 7b). As shown in Fig. 8, the spatially averaged temperature in the Indus and Ganges basins (western and eastern IGB) is reconstructed for the period of 1600-1900 using the regression equations and the reconstructed temperature in Kathmandu. The temperature in each of the 85 grid points is estimated by the correlation between individual points and spatially averaged temperature in the Indus or Ganges basin during the period of 1900-91, similar to the idea of pattern scaling widely used in climate modeling.

\section{2) Temperature DURING 1300-1599}

After conducting correlation analysis between temperature and a wide range of reconstructed climatic indices, the Pacific decadal oscillation (PDO) with +2 steps time lag is found to have the strongest correlation (MacDonald and Case 2005). The correlation coefficients with the PDO are 0.65 for the eastern IGB 


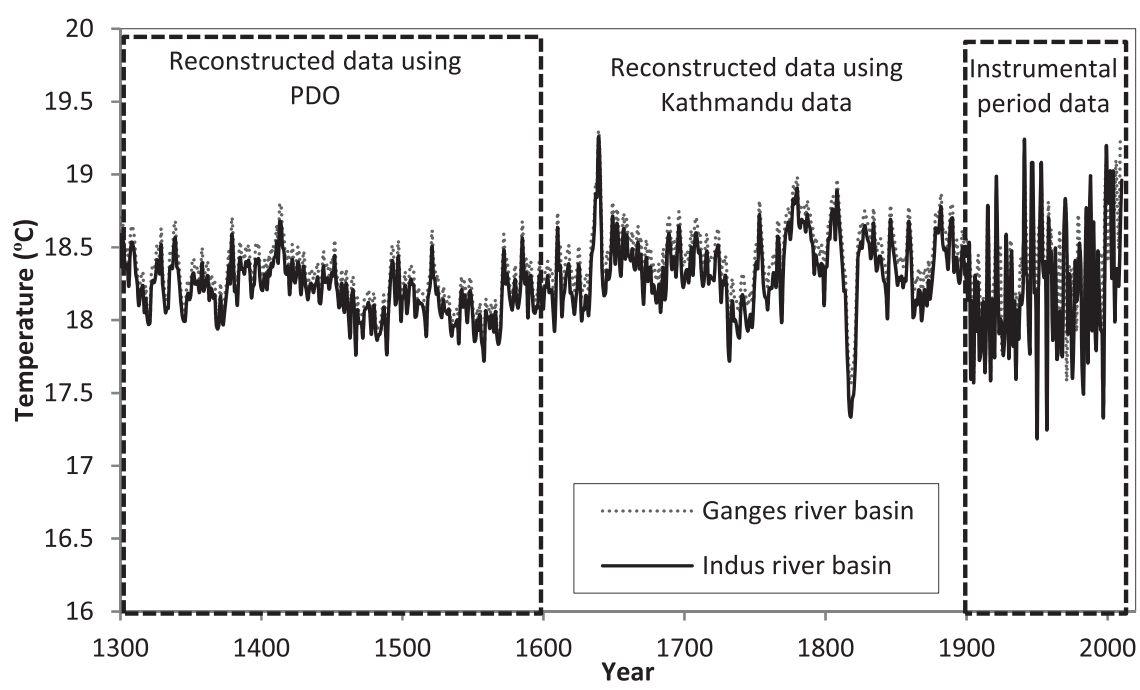

FIG. 8. The reconstructed temperature data for the IGB based on temperature in Kathmandu (1600-1900) and PDO (1300-1599).

and 0.51 for the western IGB. The reconstructed temperature (1300-1599) is obtained for each individual grid cell in the Indus and Ganges basins based on the PDO. The spatially averaged temperatures over the Indus and Ganges basins are shown in Fig. 8.

\section{b. Reconstructed precipitation}

Precipitation during 1300-1899 is reconstructed for the IGB area using the IP algorithm. The performance of the developed algorithm for retrieving precipitation from PDSI is verified during the instrumental period, which is divided into two periods: $1900-60$ and 19612010. In the first period, the modeled monthly PDSI data are directly used to retrieve monthly precipitation, which is compared with observations for evaluating the performance of the IP algorithm. In the second period, the average PDSI during the 3-month monsoon season is computed based on the modeled monthly PDSI data, then the 3-month-average PDSI is used to retrieve monthly precipitation. Therefore,

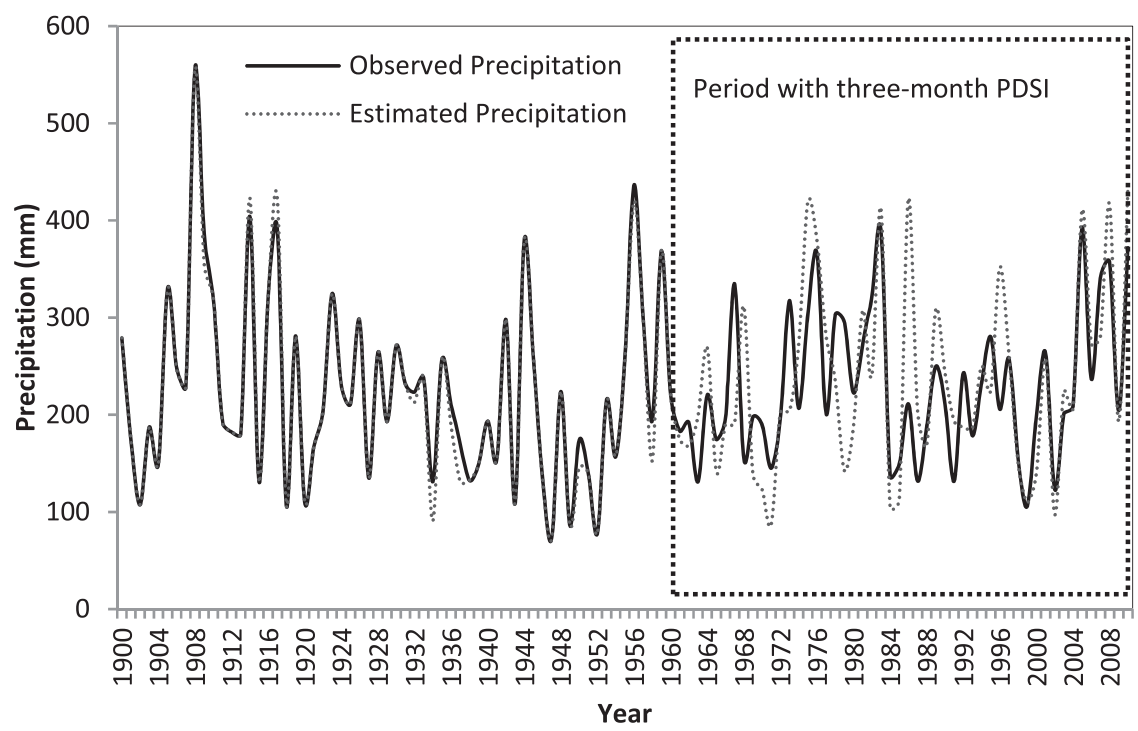

FIG. 9. Comparison of observed and retrieved monthly precipitation (gridpoint 18), where monthly precipitation is estimated from monthly PDSI during 1900-60 and 3-month PDSI during 1961-2010. 


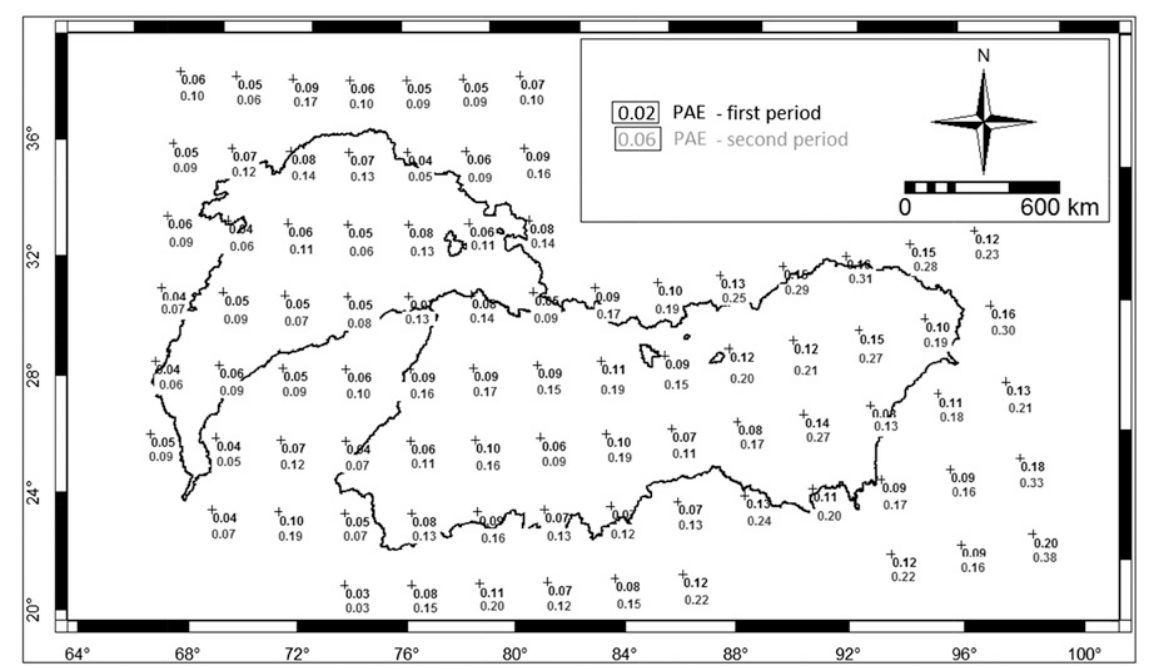

FIG. 10. Spatial variation of PAE for retrieved precipitation data. The first period (black) represents the performance of the IP algorithm for retrieving monthly precipitation from monthly PDSI. The second period (gray) represents the performance for retrieving monthly precipitation from the 3-month PDSI.

the first period is used to evaluate the performance of retrieving monthly precipitation from monthly PDSI, while the second period is used to evaluate the performance of retrieving monthly precipitation from 3-month PDSI. Results from sample gridpoint 18 are shown in Fig. 9. Figure 10 shows the percentage of average error (PAE) of each grid point for the two mentioned periods, calculated using Eq. (7) (Gyawali and Watkins 2013):

$$
\mathrm{PAE}=\frac{1}{N} \sum_{i=1}^{N}\left|\left(P_{o_{i}}-\mathrm{P}_{r_{i}}\right) / P_{o_{i}}\right|
$$

where $P_{o_{i}}$ and $P_{r_{i}}$ are observed and retrieved precipitation at month $i$, respectively, and $N$ is the total number of months. PAE for the period with monthly PDSI varies from $3 \%$ to $20 \%$. For the period with the 3 -month PDSI (1961-2010), the overall results in the IGB region are acceptable and PAE varies from $3 \%$ to $38 \%$. Figure 10 shows that PAE in the Ganges basin and mountainous area is larger than that in the Indus basin. Larger PAE values in the mountainous area are due to the higher percentage of snow in this area, which decreases the accuracy of PDSI and, subsequently, the IP algorithm (Alley 1984). Larger PAE values in the Ganges basin, in which the intensity is higher and the duration is lower, may be due to the difference of precipitation system. Figure 11 shows the spatially averaged annual precipitation over the Indus and Ganges basins and the moving average over a time window of 11 years during the reconstruction and instrumental periods. A declining trend in precipitation is observed during the 1930s for both areas.
To evaluate the impact of uncertainty in temperature reconstruction on the retrieved precipitation, the upper and lower envelopes in Fig. 7 are also utilized for estimating temperature during the reconstruction period. The corresponding retrieved precipitation is then compared with the reconstructed precipitation based on a regression-based temperature reconstruction. The mean absolute error (MAE) is $0.07 \%$ for the upper envelope and $0.06 \%$ for the lower envelope in the Ganges basin, while MAE is $1.3 \%$ for the upper envelope and $0.3 \%$ for the lower envelope in the Indus basin.

\section{c. Megadrought analysis}

Paleoclimatology provides an estimation of the past climate, and uncertainty is inevitable in the reconstructed data. The existing evidence from previous droughts or pluvial years can be used to assess the quality of the reconstructed data, particularly megadroughts. Megadrought refers to decades-long drought or multidecadal drought, emphasizing the duration of drought but not its intensity. In this study the definition of megadrought by Meehl and $\mathrm{Hu}$ (2006) is adopted, that is, the 11-yr moving average of spatially averaged precipitation anomalies is less than zero for at least 20 consecutive years.

Several megadroughts are identified based on the reconstructed precipitation data during the reconstruction period: $1308-44,1501-71$, and 1733-51 for the Indus basin and 1313-46, 1417-32, 1562-82, and 1747-66 for the Ganges basin. Based on the studies of Cook et al. (2010), the overall IGB region is affected by monsoon 

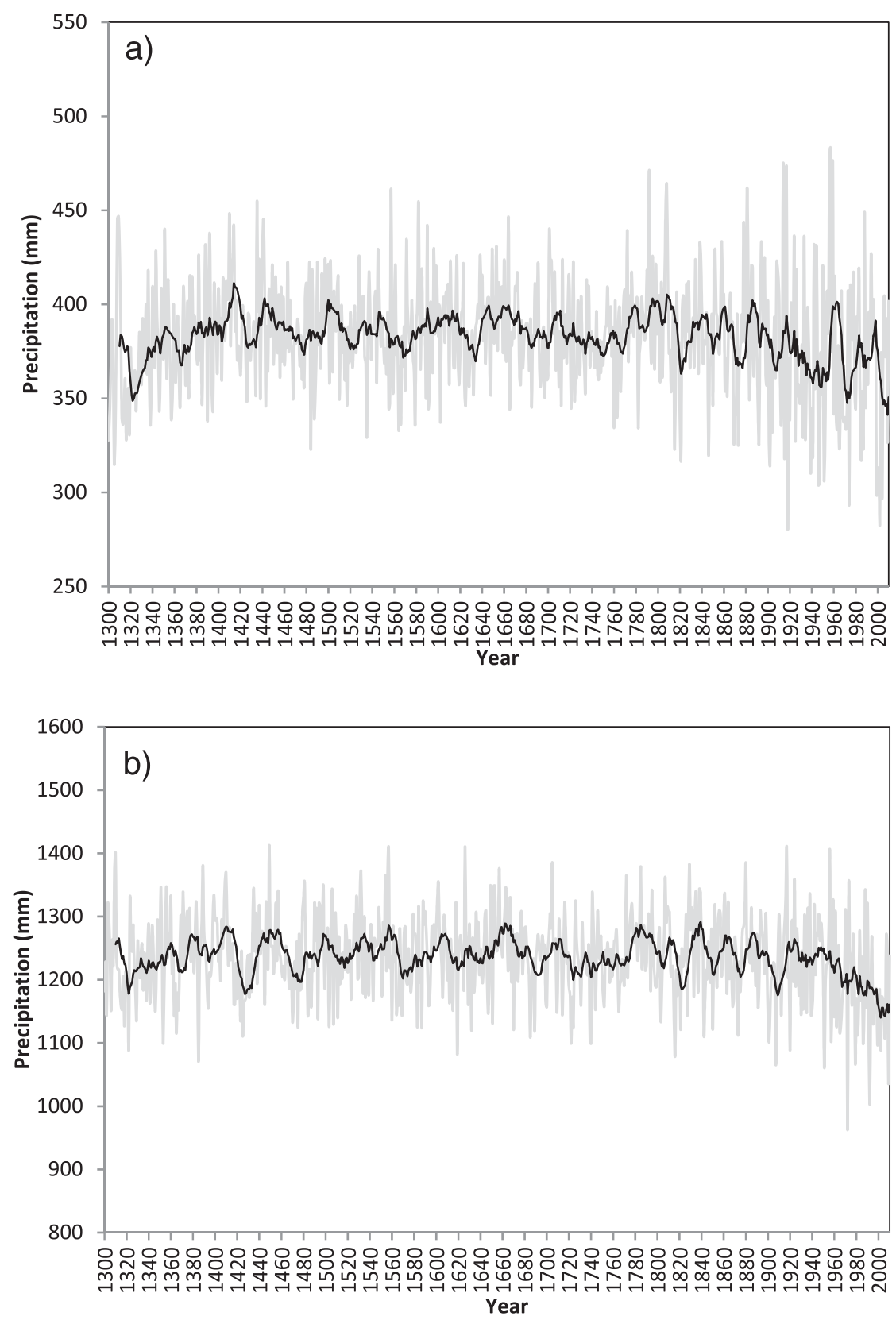

FIG. 11. Spatially averaged annual precipitation (black line) during the reconstruction and instrumental periods as well as 11-yr moving average (gray line) for (a) the Indus River basin and (b) the Ganges River basin.

failure during 1756-68 and 1876-78. The reconstructed precipitation in the current study shows that severe drought occurred during 1756-68, which was a subperiod of the megadrought in the eastern part of IGB. Figure 12 shows the precipitation anomaly during 1756-68, indicating that a pervasive drought covers a south and central area of the IGB. It is worth nothing that Fig. 12 and other raster maps are generated using kriging interpolation based on 85 grid points. Some of the grid points, especially in the western part of the IGB, show severe drought during 1876-78. Sinha et al. (2011) mentions the year 1899 as a significant monsoon failure in the area. This year is also detected in the current study. Figure 13 shows the spatial coverage of drought in 1899 using the reconstructed precipitation data. 


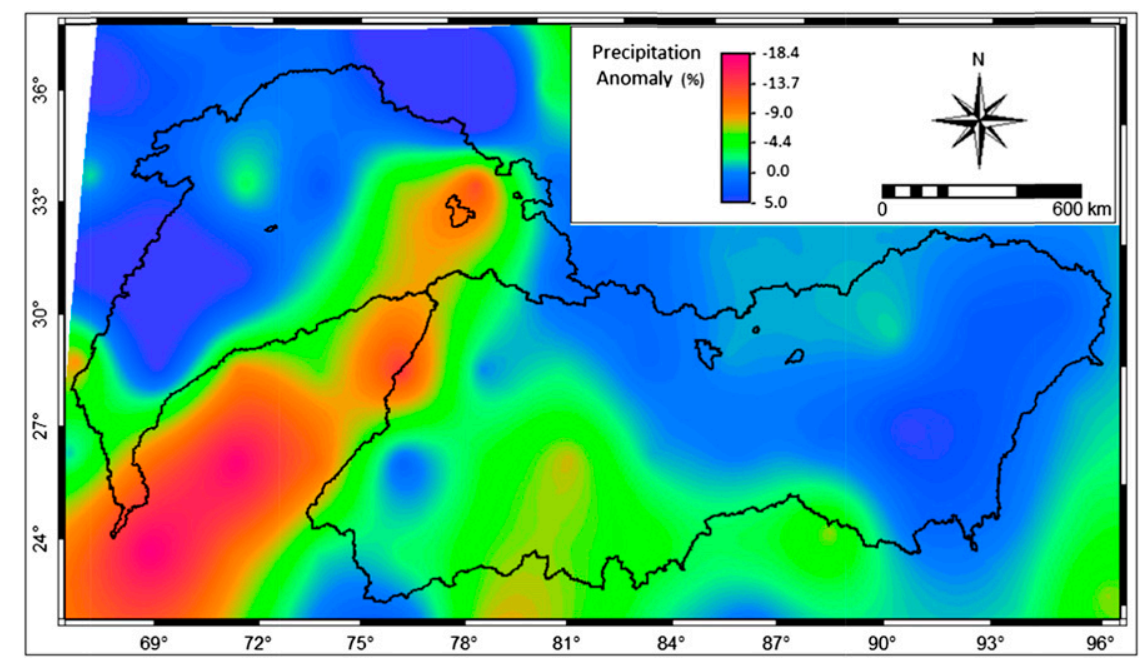

FIG. 12. Precipitation anomaly (\%) during 1756-68, reflecting pervasive drought in the IGB area.

\section{d. Precipitation trend and spatiotemporal pattern of severe drought}

The reconstructed precipitation in this study enables a spatiotemporal analysis of drought. In the IGB area, a severe drought occurs when the annual precipitation deficit, compared with the long-term average precipitation, is greater than $10 \%$ (Sinha et al. 2011). In this study, the long-term average precipitation is computed over the period of 1300-2010. Drought frequency is calculated as the percentage of years with severe droughts. Drought intensity is defined as the average precipitation deficit during all of the years identified as severe droughts. The drought frequency and intensity are quantified for two periods: 1300-1899 (the reconstruction period) and 1900-2010 (the instrumental period). Figure 14 shows the drought frequency during the two periods. As shown in the figure, the drought frequency, as well as the spatial extent, has significantly increased from the reconstruction period to the instrumental period. The drought frequency in the Indus basin is higher than that in the Ganges basin; the areal average of the drought frequency increases from $30 \%$ in 1300-1899 to 40\% in 1900-2010. As shown in Fig. 15, the magnitude and spatial extent of the drought intensity have increased from 1300-1899 to 1900-2010 as well. The areal average intensity of drought changes from $23 \%$ to $28 \% \mathrm{yr}^{-1}$ through these two periods. In general,

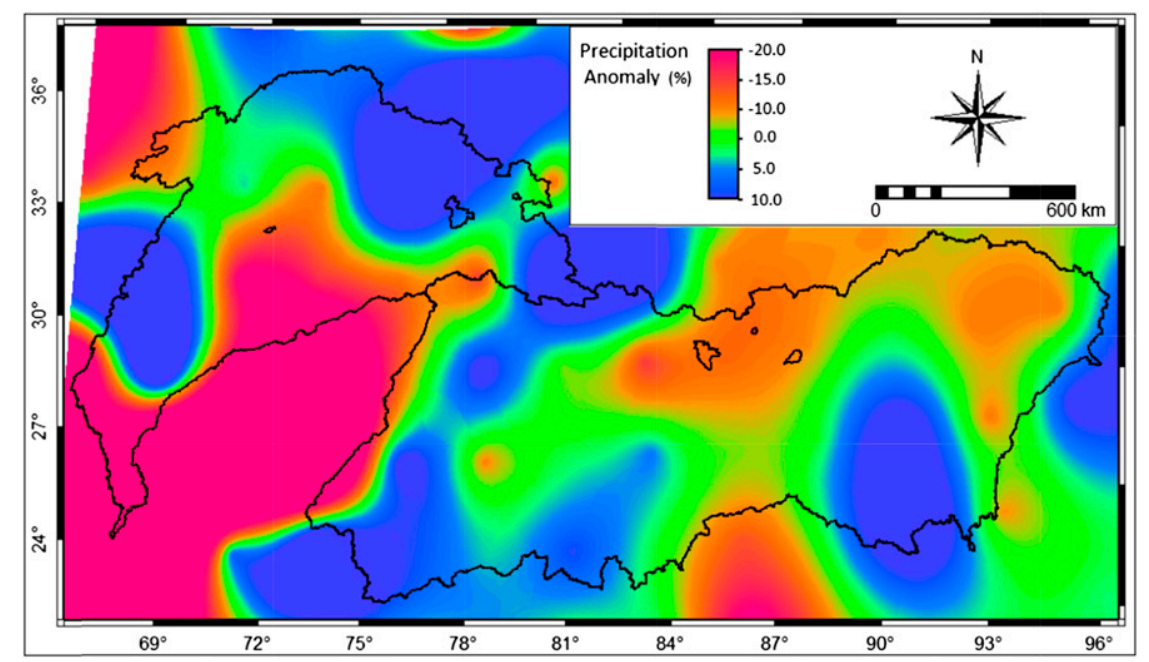

FIG. 13. Precipitation anomaly (\%) during 1899, reflecting pervasive drought in the IGB area. 

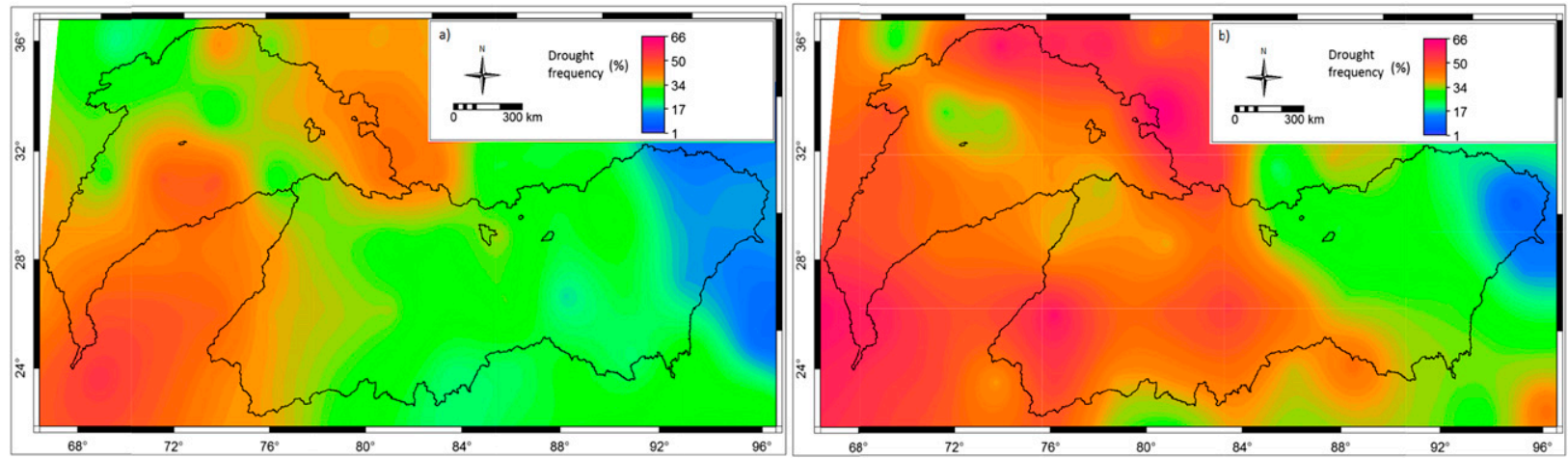

FIG. 14. Drought frequency (\%) during the periods of (a) 1300-1899 and (b) 1900-2010.

the western part of the IGB experienced more severe droughts than the eastern part of the IGB.

\section{Conclusions}

This study focuses on paleoprecipitation reconstruction in the Indus and Ganges basins for the period 13001899 using tree-ring-based PDSI. Since MADA-PDSI data have previously been reconstructed based on treering data, the paleoprecipitation reconstruction is accomplished by developing the IP algorithm. Temperature data are reconstructed through a point-by-point correlation analysis using existing reconstruction data of temperature and PDO.

Precipitation is the output of the developed IP algorithm driven by the inputs of PDSI, AWC, and temperature. The performance of the IP algorithm is validated in the instrumental period. Uncertainties in the reconstructed paleoprecipitation data mainly originate from two sources: 1) the inverse PDSI method and 2) the transforming of 3-month-averaged PDSI to monthly PDSI. Temperature reconstruction may also contribute to precipitation uncertainties; however, we find precipitation results are not sensitive to small perturbations in temperature input. In general, the uncertainty in the reconstructed annual precipitation is $3 \%-38 \%$, which varies spatially. The uncertainty is higher in the eastern IGB and in mountainous areas. Comparison of reconstructed precipitation data during 1300-1899 with other studies verifies the accuracy of the current study and also suggests that the reconstructed precipitation data are capable of detecting monsoon failures during the past millennium. As a signal of climate change, increasing intensity and frequency of severe drought in the Indus and Ganges River basins needs adaptation strategies and drought preparedness measure to secure food production in this area as one of the largest breadbaskets in the world.

Finally, it has to be noted that uncertainties in the input data may also introduce uncertainties to the paleoprecipitation reconstruction. MADA-PDSI, reconstructed temperature, and AWC are the three data inputs for the inverse PDSI modeling. Uncertainty exists in the reconstructed temperature transferred from adjacent areas using a linear correlation analysis. Grid cell-specific AWC values are assumed to be constant during the reconstruction and instrumental periods. AWC may change because of agricultural development
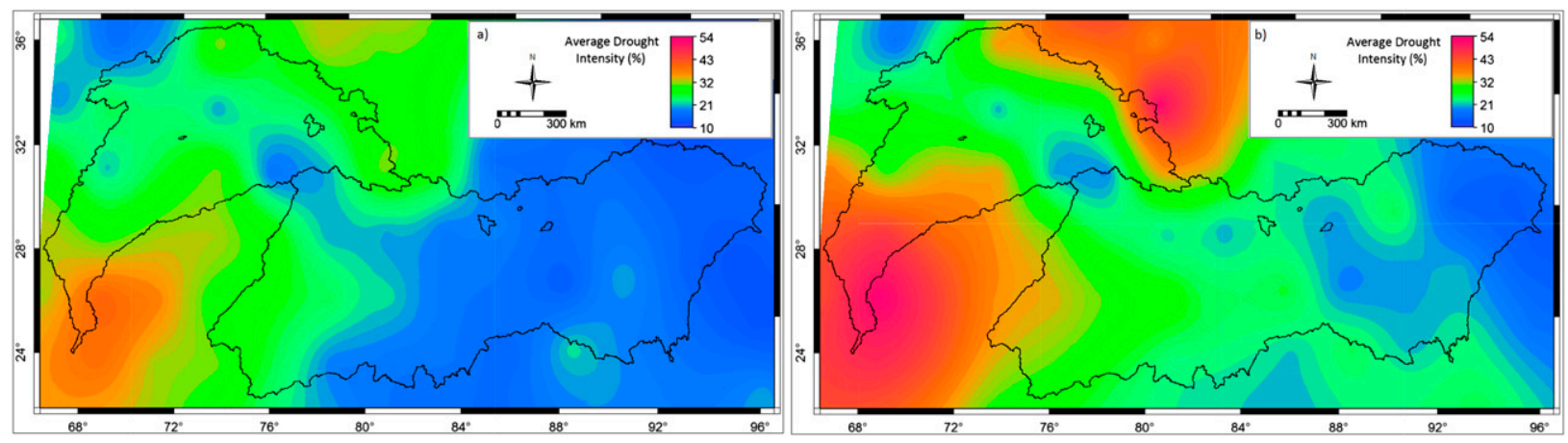

FIG. 15. Average drought intensity, which is computed the precipitation deficit compared with long-term average precipitation (\%), during the periods of (a) 1300-1899 and (b) 1900-2010. 
and other land use changes. However, the reconstructed paleoprecipitation in this study is valuable for study of past climate, especially for historical periods without weather observations. Future research could be conducted to reduce uncertainties in the input data.

Acknowledgments. The research conducted in this paper was funded by the CGIAR Research Program on Climate Change, Agriculture and Food Security (CCAFS) through the CCAFS project "Investigating the impacts of climate extremes on future water and food security" led by the International Food Policy Research Institute. We thank John Jacobi from Vanderbilt University for providing forward PDSI code and his kind support.

\section{REFERENCES}

Aggarwal, P. K., P. K. Joshi, J. S. I. Ingram, and R. K. Gupta, 2004: Adapting food systems of the Indo-Gangetic plains to global environmental change: Key information needs to a improve policy formulation. Environ. Sci. Policy, 7, 487-498, doi:10.1016/ j.envsci.2004.07.006.

Alley, W. M., 1984: The Palmer drought severity index: Limitations and assumptions. J. Climate Appl. Meteor., 23, 1100-1109, doi:10.1175/ 1520-0450(1984)023<1100:TPDSIL > 2.0.CO;2.

Briffa, K. R., T. J. Osborn, F. H. Schweingruber, I. C. Harris, P. D. Jones, S. G. Shiyatov, and E. A. Vaganov, 2001: Lowfrequency temperature variations from a northern tree ring density network. J. Geophys. Res., 106, 2929-2941, doi:10.1029/ 2000JD900617.

Cook, E. R., P. J. Krusic, and P. D. Jones, 2003: Dendroclimatic signals in long tree-ring chronologies from the Himalayas of Nepal. Int. J. Climatol., 23, 707-732, doi: 10.1002/joc. 911 .

—, K. J. Anchukaitis, B. M. Buckley, R. D. D'Arrigo, G. C. Jacoby, and W. E. Wright, 2010: Asian monsoon failure and megadrought during the last millennium. Science, 328, 486489, doi:10.1126/science. 1185188.

Dai, A., K. E. Trenberth, and T. Qian, 2004: A global dataset of Palmer drought severity index for 1870-2002: Relationship with soil moisture and effects of surface warming. J. Hydrometeor., 5, 1117-1130, doi:10.1175/JHM-386.1.

Elbert, J., and Coauthors, 2013: Late Holocene air temperature variability reconstructed from the sediments of Laguna Escondida, Patagonia, Chile $\left(45^{\circ} 30^{\prime} \mathrm{S}\right)$. Palaeogeogr. Palaeoclimatol. Palaeoecol., 369, 482-492, doi:10.1016/ j.palaeo.2012.11.013

Gadgil, S., P. N. Vinayachandran, P. A. Francis, and S. Gadgil, 2004: Extremes of the Indian summer monsoon rainfall, ENSO and equatorial Indian Ocean oscillation. Geophys. Res. Lett., 31, L12213, doi:10.1029/2004GL019733.

Golovanova, I. V., R. Y. Sal'manova, and D. Y. Demezhko, 2012: Climate reconstruction in the Urals from geothermal data. Russ. Geol. Geophys., 53, 1366-1373, doi:10.1016/ j.rgg.2012.10.009.

Gupta, R. K., P. R. Hobbs, J. K. Ladha, and S. V. R. K. Prabhakar, 2001: Resource conserving technologies: Transforming the rice-wheat systems of the Indo-Gangetic plains. APAARI Publ. 2002/1, Asia-Pacific Association of Agricultural Research
Institutions, FAO Regional Office for Asia and the Pacific, Bangkok, Thailand, 42 pp. [Available online at www.apaari.org/ wp-content/uploads/2009/05/ss_2002_01.pdf.]

Gyawali, R., and D. W. Watkins, 2013: Continuous hydrologic modeling of snow-affected watersheds in the Great Lakes basin using HEC-HMS. J. Hydrol. Eng., 18, 29-39, doi:10.1061/ (ASCE)HE.1943-5584.0000591.

Houghton, J. H., Y. Ding, D. J. Griggs, M. Nogue, P. J. van der Linden, X. Dai, K. Maskell, and C. A. Johnson, Eds., 2001: Climate Change 2001: The Scientific Basis. Cambridge University Press, 881 pp.

Hughes, M. K., X. D. Wu, X. M. Shao, and G. M. Garfin, 1994: A preliminary reconstruction of rainfall in north-central China since A.D. 1600 from tree-ring density and width. Quat. Res., 42, 88-99, doi:10.1006/qres.1994.1056.

Jacobi, J., D. Perrone, L. L. Duncan, and G. Hornberger, 2013: A tool for calculating the Palmer drought indices. Water Resour. Res., 49, 6086-6089, doi:10.1002/wrcr.20342.

Karim, A., and J. Veizer, 2002: Water balance of the Indus River basin and moisture source in the Karakoram and western Himalayas: Implications from hydrogen and oxygen isotopes in river water. J. Geophys. Res., 107, 4362, doi:10.1029/ 2000JD000253.

Kumar, K. K., B. Rajagopalan, M. Hoerling, G. Bates, and M. Cane, 2006: Unraveling the mystery of Indian monsoon failure during El Niño. Science, 314, 115-119, doi:10.1126/ science.1131152.

Li, J., S. P. Xie, E. R. Cook, G. Huang, R. D’Arrigo, F. Liu, J. Ma, and X. T. Zheng, 2011: Interdecadal modulation of El Niño amplitude during the past millennium. Nat. Climate Change, 1, 114-118, doi:10.1038/nclimate1086.

MacDonald, G. M., and R. A. Case, 2005: Variations in the Pacific decadal oscillation over the past millennium. Geophys. Res. Lett., 32, L08703, doi:10.1029/2005GL022478.

Macias-Fauria, M., A. Grinsted, S. Helama, and J. Holopainen, 2012: Persistence matters: Estimation of the statistical significance of paleoclimatic reconstruction statistics from autocorrelated time series. Dendrochronologia, 30, 179-187, doi:10.1016/ j.dendro.2011.08.003.

McGregor, S., A. Timmermann, and O. Timm, 2010: A unified proxy for ENSO and PDO variability since 1650. Climate Past, 6, 1-17, doi:10.5194/cp-6-1-2010.

Meehl, G. A., and A. Hu, 2006: Megadroughts in the Indian monsoon region and southwest North America and a mechanism for associated multidecadal Pacific sea surface temperature anomalies. J. Climate, 19, 1605-1623, doi:10.1175/JCLI3675.1.

Mishra, A. K., and V. P. Singh, 2010: A review of drought concepts. J. Hydrol., 391, 202-216, doi:10.1016/j.jhydrol.2010.07.012.

Nachtergaele, F., H. V. Velthuizen, L. Verelst, and D. Wiberg, cited 2012: Harmonized World Soil Database version 1.2. FAO/ IIASA/ISRIC/ISSCAS/JRC. [Available online at www.fao.org/ soils-portal/soil-survey/soil-maps-and-databases/harmonizedworld-soil-database-v12/en/.]

Nandakumar, T., K. Ganguly, P. Sharma, and A. Gulati, 2010: Food and nutrition security status in India, opportunities for investment partnerships. ADB Sustainable Development Working Paper Series 16, Asian Development Bank, Manila, Philippines, 40 pp. [Available online at www.adb.org/ publications/food-and-nutrition-security-status-india-opportunitiesinvestment-partnerships.]

Palmer, W. C., 1965: Meteorological drought. U.S. Weather Bureau Research Paper 45, 65 pp. [Available online at http:// lwf.ncdc.noaa.gov/temp-and-precip/drought/docs/palmer.pdf.] 
Prasad, S., and Coauthors, 2014: Prolonged monsoon droughts and links to Indo-Pacific warm pool: A Holocene record from Lonar Lake, central India. Earth Planet. Sci. Lett., 391, 171182, doi:10.1016/j.epsl.2014.01.043.

Ryu, J. H., M. D. Svoboda, J. D. Lenters, T. Tadesse, and C. L. Knutson, 2010: Potential extents for ENSO-driven hydrologic drought forecasts in the United States. Climatic Change, 101, 575-597, doi:10.1007/s10584-009-9705-0.

Shi, F., Y. Bao, and L. V. Gunten, 2012: Preliminary multiproxy surface air temperature field reconstruction for China over the past millennium. Sci. China Earth Sci., 55, 2058-2067, doi:10.1007/s11430-012-4374-7.

Sikka, A. K., and C. Ringler, 2009: Introduction to special issue. Int. J. River Basin Manage., 7, 107-110.

Sinha, A., L. Stott, M. Berkelhammer, H. Cheng, R. L. Edwards, B. Buckley, M. Aldenderfer, and M. Mudelsee, 2011: A global context for megadroughts in monsoon Asia during the past millennium. Quat. Sci. Rev., 30, 47-62, doi:10.1016/ j.quascirev.2010.10.005.

Tan, M., T. S. Liu, J. Hou, X. Qin, H. Zhang, and T. Li, 2003: Cyclic rapid warming on centennial-scale revealed by a 2650 -year stalagmite record of warm season temperature. Geophys. Res. Lett., 30, 1617, doi:10.1029/2003GL017352.
Thornthwaite, C. W., 1948: An approach toward a rational classification of climate. Geogr. Rev., 38, 55-94, doi:10.2307/210739.

Villalba, R., and Coauthors, 2012: Unusual Southern Hemisphere tree growth patterns induced by changes in the southern annular mode. Nat. Geosci., 5, 793-798, doi:10.1038/ ngeo1613.

Wang, D., M. Hejazi, X. Cai, and A. J. Valocchi, 2011: Climate change impact on meteorological, agricultural, and hydrological drought in central Illinois. Water Resour. Res., 47, W09527, doi:10.1029/2010WR009845.

Willmott, C. J., and K. Matsuura, cited 2012: Terrestrial air temperature and precipitation: Monthly and annual time series (19002010). Center for Climatic Research, University of Delaware. [Available online at http://climate.geog.udel.edu/ climate/.]

Yadav, R. R., K. G. Misra, B. S. Kotlia, and N. Upreti, 2014: Premonsoon precipitation variability in Kumaon Himalaya, India over a perspective of $\sim 300$ years. Quat. Int., 325, 213-219, doi:10.1016/j.quaint.2013.09.005.

Yi, L., H. Yu, J. Ge, Z. Lai, X. Xu, L. Qin, and S. Peng, 2011: Reconstructions of annual summer precipitation and temperature in north-central China since $1470 \mathrm{AD}$ based on drought/flood index and tree-ring records. Climatic Change, 110, 469-498, doi:10.1007/s10584-011-0052-6. 